\title{
The effect of dimensional preference on reversal shift behavior of young children'
}

LYNN M. JAMES, THOMAS G. O'BRIEN, and JOSEPH F. BRINLEY, St. Louis University, St. Louis, Mo. 63108

Twenty-eight kindergarten children served as $S s$ in a discrimination reversal task. Each $S$ was given a preference test to determine the probability of attending to a particular dimension. It was hypothesized that dimensional preference would affect original learning and the tendency to reverse. The results supported the first hypothesis but not the second. It was further found that the effect of preference was primarily due to the performance of reversers. The data were interpreted in favor of a mediational explanation of developmental differences in discrimination learning.

The purpose of this study was to determine whether dimensional preference for either color or form would affect the transfer of learned discriminations in an optional reversal learning task employing pairs of stimulus objects which varied simultaneously on both dimensions. The Ss were kindergarten children. Children at this age may be less likely than older children to exercise the reversal option in such tasks (Kendler \& Kendler, 1962). Kendler \& Kendler (1962) hypothesized that younger children are less likely to reverse because they are less likely to acquire and/or to employ mediational processes. The results of the present study are evidence concerning the nature of these mediational processes. According to the Kendlers, mediational mechanisms comprise abstract representations which provide additional cues for performance during the transfer phase of the experiment. Alternative interpretations (e.g., Zeaman \& House, 1963) suggest that attentional mechanisms rather than abstract representational responses are involved. According to this latter viewpoint, age differences in the tendency to reverse are associated with variations in the strength of attentional mechanisms rather than variations in the utilization of abstract representations.

\section{SUBJECTS}

The Ss for this experiment were 28 kindergarten children ranging in age from 5-6 to 6-2. The Ss were randomly assigned to two treatment groups: Preferred (P) which received training in the preferred dimension and Nonpreferred (NP) which received training in the nonpreferred dimension. There were 14 Ss in each group.

\section{MATERIALS}

The cards for the preference test consisted of three cutouts arranged triangularly on a white piece of posterboard. The cutouts were of three different forms (circles, triangles, and squares) and three different colors (yellow, green, and blue). On each card there were two figures identical in form and two identical in color.

Ten cards were used for training and testing on the discrimination task. Five of these cards consisted of a blue circle and a red square, varying in position, cemented about an inch apart on gray posterboard. The other five consisted of a red circle and a blue square. Thus, the stimulus objects varied along two dimensions, color and form.

\section{PROCEDURE}

Preference Testing

At least two days, but not more than a week prior to testing, each $\mathrm{S}$ was given a preference test. This test required the $S$ to look at each card and choose the two objects which looked alike to him. The preference test was designed to determine whether the $\mathrm{S}$ preferred color to form or vice versa.
On the basis of the results of this test Ss were assigned to one of the two conditions.

Learning and Reversal

The testing session was divided into three phases. During Phase 1 the $\mathrm{S}$ was reinforced for choosing one of the stimulus objects within a particular dimension (e.g., square). When the discrimination was learned to a nine out of 10 criterion, the reinforcement contingencies were reversed. This began Phase 2 of the experiment and each $S$ was required to learn the new discrimination to a nine-out-of-10 criterion. When the $S$ reached criterion in Phase 2, Phase 3 began. This phase was the test phase and was designed to determine whether the $S$ had chosen to reverse or nonreverse during Phase 2 . This is the typical optional reversal procedure and is explained in greater detail in Kendler, Kendler, \& Leanard, 1962.

$$
\text { RESULTS }
$$

In the preferences test, four of the 28 Ss responded to color rather than to form. Two of these four were assigned to the preferred condition and the other two to the nonpreferred condition.

In Phase 1 of the experiment, two Ss failed to reach the nine out of 10 criterion in 100 trials. These Ss were dropped from the experiment and replaced with two others. Mean trials and SDs for Ss trained in the preferred and nonpreferred dimensions were $7.57(11.32)$ and 21.67 (18.04), respectively. The Mann-Whitney $U$ indicated a significant effect of preference $(z=-2.67, p<.01)$. Ss trained in their preferred

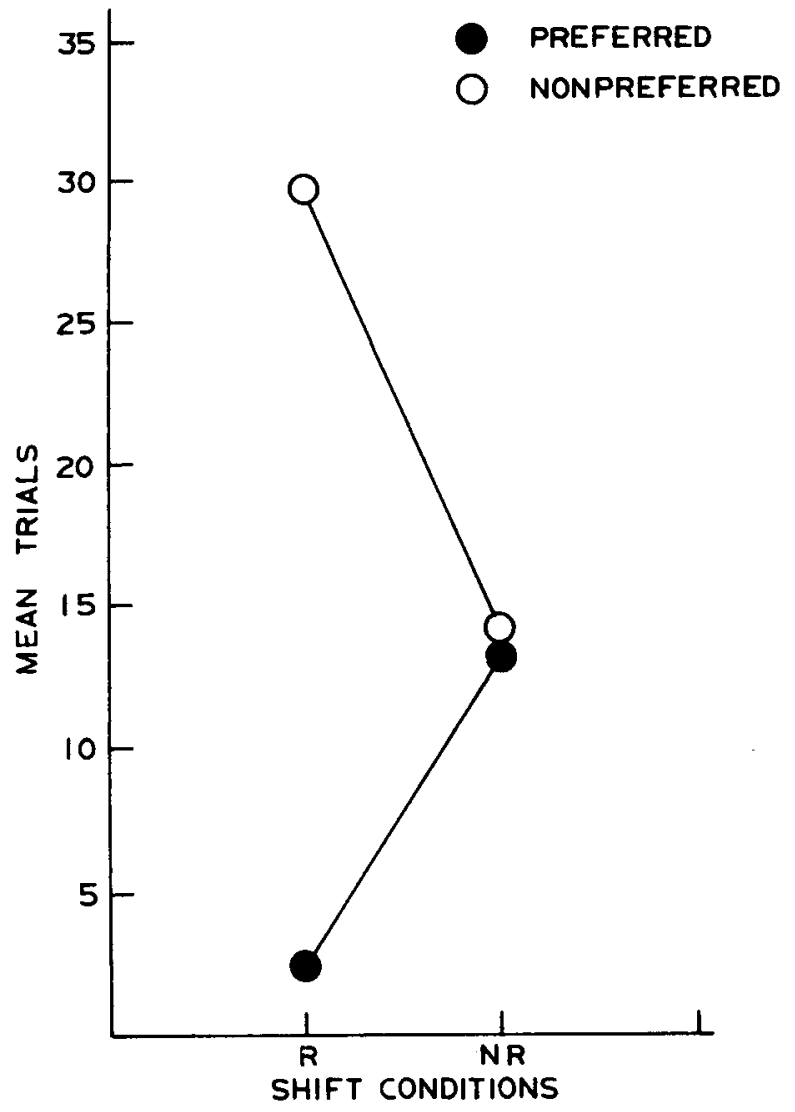

Fig. 1. Phase 1: Mean Trials beyond criterion by Shift Condition. 
context condition, tho was $-.58(\mathrm{p}<.05)$; for the no-context condition, rho was -.25 (n.s.). Longer messages were accompanied by a decrease in error choices when impressions were coded in context. The relationship was not significant when impressions were coded independently of context.

The results supported the hypothesis that impressions of people coded with reference to an array of people are transmitted more efficiently than impressions coded independently of the array. Significantly fewer words-per-message coded in context generated a similar number of identification errors as did longer messages coded out of context resulting in greater transmission efficiency for context encoders.

The rank order correlations between message length and errors in each group suggest the reasons for this difference. The context coders were able to encode the characteristics which most easily differentiated each person. This comparison process permitted encoders to use only those words necessary to depict their impressions. When longer messages were generated they tended to result in fewer decoding errors so that efficiency did not decrease. Subjects in the no-context condition were unable to encode the most distinctive features of each person since they lacked a basis of comparison of one person with another. These encoders resorted to longer messages, the extra words being irrelevant for accurate decoding since length and errors were not related. Increased length without decreased errors resulted in lowered efficiency.

The application of a communication paradigm to studies of person perception seems quite apparent. Advantages of this approach are implied by Maclay \& Newman (1960) who suggest that motivational variables, personality characteristics of communicators, and sociocultural variables may influence the nature of communication. Schroder, Driver, \& Streufert (1967) indicate that interactions between environmental and personality variables in communication is the rule rather than

\section{Continued from page 56$)$}

dimension took less time to learn the initial discrimination than did Ss trained in their nonpreferred dimension.

There was no treatment effect on the choice to reverse or nonreverse. Ss reversed just as frequently when trained in the nonpreferred dimension. Seven Ss trained in their preferred dimension chose to reverse as did seven Ss trained in their nonpreferred dimension.

A further analysis which divided Ss into four groups, Reversers (Preferred and Nonpreferred) and Nonreversers (Preferred and Nonpreferred), yielded Mean trials and SDs of $2.42(5.18), 29.57$ (17.39), 12.71 (13.37), and 13.77 (14.35), respectively. Bartlett's test for homogeneity of variance yielded positive results and for this reason, a square root transformation of the scores was made. An analysis of variance indicated an effect of preference $(\mathrm{F}=7.53, \mathrm{df}=1 / 24$, $p<.025)$ and an interaction effect $(F=6.14, \mathrm{df}=1 / 24$, $\mathrm{p}<.025)$. Fig. 1 graphs these data. This analysis revealed that the effect of preference was due to the performance of those Ss who reversed.

\section{DISCUSSION}

The results of this study supported the hypothesis that dimensional preference has an effect on discrimination learning. This has been reported a number of times (O'Brien, 1966; Smiley \& Weir, 1967; Suchman \& Trabasso (1966); and Wolff, 1966).

The data, however, do not support the hypothesis that Ss trained in their preferred dimension will more likely exercise the reversal option. Furthermore, it was found that dimensional preference affected original learning only for those Ss who subsequently chose to reverse. These results are difficult to explain in terms of attention theory. It would seem, according to that viewpoint, that the group trained in their preferred dimension would show more rapid initial learning and a greater proportion of reversers. Attention theory would have particular difficulty in accounting for the the exception. Communicating about impressions of people seems to be a natural and ubiquitous process. Consequently, the more reliable and objective measures from communication research might be brought to bear on studies of impression formation as revealed in message characteristics to provide increased understanding of social perception phenomena.

\section{REFERENCES}

BOYD, J. E., \& JACKSON, D. N. The perceived structure of social attitudes and personality: A multidimensional scaling approach. Multivariate Behavioral Research, 1967, 2, 281-297.

BROWN, R. W. Social psychology. New York: The Free Press, 1965.

BROWN, R. W., \& LENNEBERG, E. H. A study in language and cognition. Journal of Abnormal \& Social Psychology, 1954, 49, 454-462.

CARROLL; J. B., \& CASAGRANDE, J. B. The function of language classifications in behavior. In E. E. Maccoby, T. M. Newcomb, and E. L. Hartley (Eds.), Readings in social psychology. New York: Holt, 1958. Pp.18-31.

FRICK, F. C. Information theory. In S. Koch (Ed.), Psychology: A study of a science. Vol. 2. General systematic formulations, learning, and special processes. New York: McGraw-Hill, 1959. Pp. 611-636.

JACKSON, D. N. A modern strategy for personality assessment: The Personality Research Form. Paper read at American Psychological Association, New York, September, 1966.

LANTZ, D. L. Color naming and color recognition: a study in the psychology of language. Unpublished doctoral dissertation, Harvard University, 1963.

MACLAY, H. A descriptive approach to communication. In N. F, Washburne (Ed.), Decisions, values, and groups. Vol. 2. New York: Pergamon Press, 1962. Pp. 201-226.

MACLAY, H., \& NEWMAN, $S$. Two variables affecting the message in communication. In D. Willner (Ed.), Decisions, values, and groups. Vol. 1. New York: Pergamon Press, 1960. Pp. 218-228.

SCHRODER, H. M., DRIVER, M. J., \& STREUFERT, S. Human information processing. New York: Holt, Rinehart, \& Winston, 1967. NOTE

1. This work was supported in part by grants from the Alcoholism and Drug Addiction Research Foundation of Ontario, and by the Canada Council.

pertorman

pertormance of Ss trained on the nonpreferred dimension. Amo showed the greatest difficulty in original learning were more likely to elect the reversal option.

Although these data are by no means conclusive, they can be taken in support of a theory such as the Kendlers', which emphasizes stages of development and the existence of a transition period when mediational processes, in addition to attentional biases, begin to influence the performance of children in discrimination learning tasks.

\section{REFERENCES}

KENDLER, H. H., \& KENDLER, T. S. Vertical and horizontal processes in problem solving. Psychological Review, 1962, 69, 1-15.

KENDLER, H. H., KENDLER, T. S., \& LEANARD, B. Mediated responses to size and brightness as a function of age. American Journal of Psychology, 1962, 75, 571-586.

O'BRIEN, T. Dimensional preference effect on reversal shifts of first and second graders. Unpublished Master's Thesis, St. Louis University, 1966.

SMILEY, S., \& WEIR, M. W. The role of dimensional dominance in reversal and nonreversal shift behavior. Journal of Experimental Child Psychology, 1967, 5, 296-307.

SUCHMAN, R., \& TRABASSO, T. Stimulus preference and cue function in young children's concept attainment. Journal of Experimental Child Psychology, 1966, 3, 188-198.

WOLFF, $J$. The role of dimensional preferences in discrimination learning. Psychonomic Science, 1966, 5, 555-556.

ZEAMAN, D., \& HOUSE, B. The role of attention in retardate discrimination learning. In N. R. Ellis (Ed.), Handbook of mental deficiency. New York: McGraw-Hill, 1963. NOTE

1. This study is based primarily on a thesis submitted by the first author, now Lynn McLaughlin, to the Graduate School, St. Louis University, in partial fulfillment of the requirements for the Master of Science Degree. 